\title{
Modulation of Antioxidant Enzymatic Activities by Certain Antiepileptic Drugs (Valproic Acid, Oxcarbazepine, and Topiramate): Evidence in Humans and Experimental Models
}

\author{
Noemí Cárdenas-Rodríguez, ${ }^{1}$ Elvia Coballase-Urrutia, ${ }^{1}$ Liliana Rivera-Espinosa, ${ }^{2}$ \\ Arantxa Romero-Toledo, ${ }^{1}$ Aristides III Sampieri, ${ }^{3}$ Daniel Ortega-Cuellar, ${ }^{4}$ \\ Hortencia Montesinos-Correa, ${ }^{5}$ Esaú Floriano-Sánchez, ${ }^{6}$ and Liliana Carmona-Aparicio ${ }^{1}$ \\ ${ }^{1}$ Laboratory of Neurochemistry, National Institute of Pediatrics, 04530 DF, Mexico \\ ${ }^{2}$ Laboratory of Pharmacology, National Institute of Pediatrics, 04530 DF, Mexico \\ ${ }^{3}$ Laboratory of Molecular Biology and Genomics, Faculty of Sciences, University City, UNAM, 04150 DF, Mexico \\ ${ }^{4}$ Laboratory of Experimental Nutrition, National Institute of Pediatrics, 04530 DF, Mexico \\ ${ }^{5}$ Service of Endocrinology, National Institute of Pediatrics, 04530 DF, Mexico \\ ${ }^{6}$ Section of Research and Graduate Studies, IPN, 11430 DF, Mexico
}

Correspondence should be addressed to Liliana Carmona-Aparicio; c_apariccio@yahoo.com.mx

Received 14 September 2013; Revised 15 November 2013; Accepted 18 November 2013

Academic Editor: José Pedraza-Chaverri

Copyright (C) 2013 Noemí Cárdenas-Rodríguez et al. This is an open access article distributed under the Creative Commons Attribution License, which permits unrestricted use, distribution, and reproduction in any medium, provided the original work is properly cited.

It is estimated that at least 100 million people worldwide will suffer from epilepsy at some point in their lives. This neurological disorder induces brain death due to the excessive liberation of glutamate, which activates the postsynaptic N-methyl-D-aspartic acid (NMDA) receptors, which in turn cause the reuptake of intracellular calcium (excitotoxicity). This excitotoxicity elicits a series of events leading to nitric oxide synthase (NOS) activation and the generation of reactive oxygen species (ROS). Several studies in experimental models and in humans have demonstrated that certain antiepileptic drugs (AEDs) exhibit antioxidant effects by modulating the activity of various enzymes associated with this type of stress. Considering the above-mentioned data, we aimed to compile evidence elucidating how AEDs such as valproic acid (VPA), oxcarbazepine (OXC), and topiramate (TPM) modulate oxidative stress.

Dedicated to Dr. Bernardino Huerta-Gertrudis (in memoriam)

\section{Introduction}

Neurological diseases are a major cause of health concerns at different life stages and lead to considerable utilization of medical resources [1]. Epilepsy is one of the most common neurological disorders in both children and adults $[2,3]$. The term epilepsy describes a group of disorders characterized by the presence of chronic, recurrent, and paroxysmal alterations of the motor and sensory neurological functions secondary to a disorder in the electrical activity of a neuron population [4]. The term epileptic syndrome refers to various disorders characterized by a group of signs and symptoms that occur simultaneously. These signs include the type of crisis, causes, anatomic aspects, precipitating factors, age of onset, severity, prognostics, chronicity, and electroencephalographic activity, and the clinical characteristics are identified based on the patient's age $[2,5]$.

Epileptic seizures and syndromes are classified according to the International League Against Epilepsy (ILAE), using genetic studies and electroclinical, neuropsychological, and neuroimaging research. Epilepsy can be divided, based on its 
etiology, into idiopathic disease or disease associated with a hereditary predisposition, as symptomatic or associated with any event that damages the brain, and as cryptogenic or of unknown cause $[6,7]$.

Currently, the epilepsy prevalence is reported to be five to 10 cases per 1,000 individuals. It is estimated that at least 100 million people worldwide will present with epilepsy at a certain life stage $[4,8]$. The ILAE reports that the disease prevalence lies between four and 10 cases per 1,000 individuals, and the incidence lies between 20 and 70 cases per 100,000 individuals per year. The prevalence rate in Latin-American countries is the highest, in the range of 14 to 57 per 1,000 individuals $[6,7]$.

Epilepsy control using antiepileptic drugs (AEDs) depends on several factors: efficacy, side effects of the hormonal alteration, teratogenicity, pharmacokinetics, interactions between AEDs or other drugs, serum levels, cost, and the neurologist's experience with AED use [9]. The patient may respond in three different manners: remitting seizures spontaneously (without AED use), responding adequately to $\mathrm{AED}$ administration, or presenting refractoriness to the treatment drug. The most commonly used AEDs are valproic acid (VPA), oxcarbazepine (OXC), and topiramate (TPM), which are considered the first-option treatments for the diverse manifestations of this pathology.

A wide variety of AEDs have been divided into generations according to their date of introduction to clinical use. These agents are categorized as first- (1857-1978), second(1993-2009), and third- (2009 to date) generation AEDs. The second- and third-generation drugs are described in Table 1 $[10,11]$.

\section{Overview of Valproic Acid, Oxcarbazepine, and Topiramate}

VPA is a carboxylic acid composed of eight carbons and is used to treat several types of epilepsy due to its broad action spectrum and efficiency [12] (Figure 1(a)). The mechanism of action, similarly to that of other AEDs, is not fully known; however, it has been reviewed in various articles. These reports can be divided into two groups: studies suggesting that VPA increases gamma aminobutyric acid (GABA) transmission and research indicating that this AED may directly interact with the neuronal membrane. Löscher [12] studied VPA interference with GABAergic transmission in 1993. This report is based on the observation that VPA increases the levels of the inhibitory neurotransmitter GABA [12]. Other researchers have confirmed Löscher's studies [13-15]. This effect can be produced either by glutamate decarboxylase activation [16, 17]; by the inhibition of GABA-degrading enzymes such as GABA aminotransferase [17], succinic semialdehyde dehydrogenase [18], aldehyde reductase [19], and $\alpha$-ketoglutarate dehydrogenase [17]; or by an increase in glutaminase activity [20]. Alternative mechanisms involve potentiation of the postsynaptic response of GABA, GABA receptor modulation, and depolarization induced by $\mathrm{N}$ methyl-D-aspartic acid (NMDA) [21-23].

With respect to the mechanism of VPA interactions with the neuronal membrane, it has been reported that this
TABLE 1: Primary second- and third-generation AEDs (listed in chronological order). Modified from Shorvon (2009) and Löscher and Schmidt (2011) [10,11].

\begin{tabular}{lc}
\hline Second generation & Third generation \\
\hline & Vigabatrin \\
Chlordiazepoxide & Zonisamide \\
Sulthiame & Lamotrigine \\
Diazepam & Oxcarbazepine \\
Carbamazepine & Felbamate \\
Valproate & Gabapentin \\
Clonazepam & Topiramate \\
Clobazam & Tiagabine \\
& Levetiracetam \\
& Pregabalin \\
& Rufinamide \\
& Lacosamide \\
\end{tabular}

AED decreases the excitatory synaptic potential necessary for the synchronization network and the neuronal firing in the substantia nigra [24-26]. VPA also activates conductance in the potassium channels and interferes with other biochemical pathways related to energy metabolism in the brain. However, to date, this activity has not been proven to be an additional mechanism of AED action [27].

OXC was developed as a carbamazepine analog (Figure 1(b)) [28], and its pharmaceutical activity occurs mainly through its active metabolite, 10,11-dihydro-10hydroxy-carbazepine (Figure 2). The mechanisms of action have not been clarified, but it is reported that the principal mechanism involves a blockade of voltage-dependent sodium [29]. In vitro electrophysiological and animal studies have demonstrated that this AED activity is based on the interference with transmembranal sodium, calcium, and potassium (i.e., voltage-dependent) ionic currents. These agents also modify the release of certain neurotransmitters, such as glutamate $[29,30]$.

TPM is a monosaccharide substituted with sulfate groups [2,3:4,5-bis-O-(1-methylethylidene)-beta-D-fructopyranose sulfamate] (Figure 1(c)). Five mechanisms that reportedly contribute to its antiepileptic action are as follows: blockage of the sodium channels, which reduces the duration and frequency of the action potentials [31]; a positive modulating effect of the $\mathrm{GABA}_{\mathrm{A}}$ receptors $[32,33]$; inhibition of the ionotropic glutamate receptors alpha-amino-3-hydroxy-5methyl-4-isoxazolepropionic acid receptor (AMPA)/kainate; a negative modulatory effect of the calcium channels activated by L-type voltage; and inhibition of carbonic anhydrase subtypes II and IV [32].

\section{Oxidative Stress and Its Role in Epilepsy}

In the last two decades, the study of ROS and reactive nitrogen species (RNS) has sparked great interest in clinical 


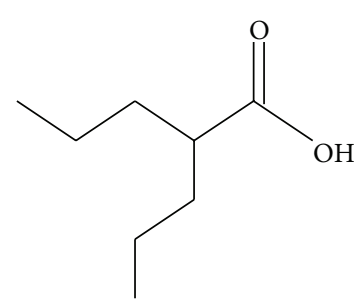

(a)

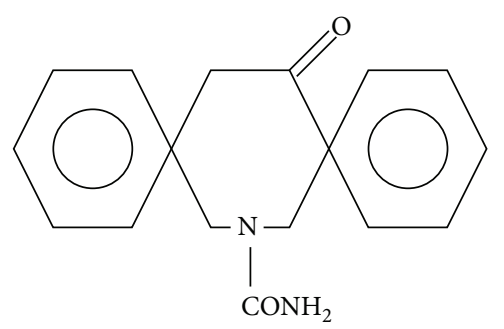

(b)

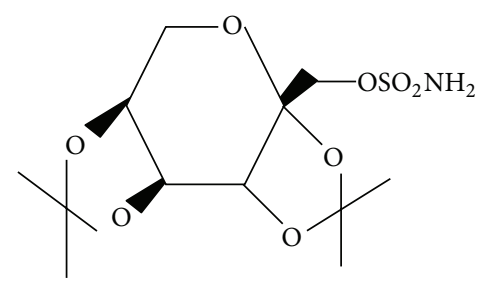

(c)

FIgURE 1: Chemical structures of (a) VPA, (b) OXC, and (c) TPM.

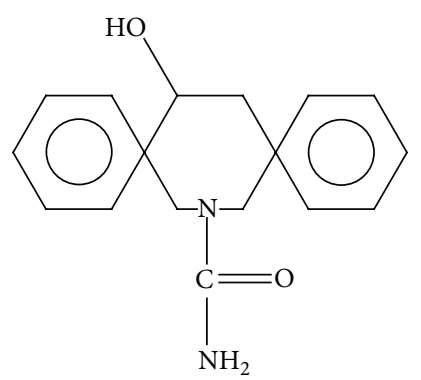

Figure 2: Chemical structure of 10,11-dihydro-10-hydroxycarbazepine, main active metabolite of OXC.

and experimental medicine. Both species are (a) generated during the irradiation of ultraviolet (UV) light, X-rays, and gamma rays, (b) products of reactions catalyzed by metals, (c) present in air pollutants; (d) produced by neutrophils and macrophages during inflammation, and (e) byproducts of reactions catalyzed by the electron carriers in the mitochondria [34].

ROS and RNS are known for their dual role in biological systems, as they can be beneficial or harmful. The beneficial effects of ROS can be observed in their physiological role in numerous cellular responses and cell signaling systems. By contrast, at high concentrations, ROS can be important mediators of cell damage to various structures such as lipids, proteins, and nucleic acids. The beneficial effects of ROS are supplemented by the action of nonenzymatic antioxidants and by the antioxidant enzyme system. Despite the presence of the antioxidant defense system to combat oxidative damage caused by ROS, this damage accumulates throughout life [34].

The imbalance between the ROS and RNS levels (such as superoxide, radical $\mathrm{O}_{2}{ }^{\bullet-}$; hydrogen peroxide, $\mathrm{H}_{2} \mathrm{O}_{2}$; hydroxyl radical, $\mathrm{HO}^{\circ}$; and nitric oxide, $\mathrm{NO}^{\circ}$ ) and the cellular antioxidant defense system (superoxide dismutase, SOD; catalase, CAT; glutathione peroxidase, GPx; glutathione reductase, GR; and glutathione-S-transferase, GST) is defined as "oxidative stress" [34]. Because this disequilibrium can appear at the cellular level (involving the mitochondria, cytochrome P450 system, peroxisomes, and activation of inflammatory cells [35]), it is involved in the development of several diseases such as cancer, atherosclerosis, and arthritis and in neurodegenerative disorders such as epilepsy $[34,36]$.

The participation of oxidative stress in diseases of the central nervous system (CNS) is well established [37, 38]. The brain is highly sensitive to oxidative damage because this organ contains a large number of easily oxidized fatty acids (20:4 and 20:6) and a limited antioxidant system [37].

Oxidative stress is strongly implicated during seizures induced by excitotoxicity, due to mitochondrial ROS generation. Since the beginning of the 1990s, oxidative stress has been associated with neuronal hyperexcitation caused by CNS diseases [39]. Dalton, in 1995, was the first to identify brain damage induced by the presence of oxidative stress in an animal experimental model [40].

The presence of $\mathrm{NO}^{\circ}$ is known to be a cause of seizures [41]. $\mathrm{NO}^{\bullet}$ is formed from high concentrations of inducible nitric oxide synthase (iNOS). The role of oxidative stress in pentylenetetrazole-induced epilepsy has been proven in rodents [42-44]. The increased activity of glutamatergic systems induces status epilepticus and causes an energy imbalance, increasing ROS formation [45]. Several studies have linked seizures and cell damage to the excitotoxicity induced by pentylenetetrazole [46]. Seizures are linked to the increased release of glutamate and NMDA receptor activation. In fact, during epileptic seizures induced by different models, there is an extracellular $\mathrm{Ca}^{2+}$ concentration decrease and a cytosolic $\mathrm{Ca}^{2+}$ concentration increase [47].

The effects mediated by $\mathrm{Ca}^{2+}$ during excessive glutamate receptor activation (excitotoxicity) lead to neuronal degeneration and give rise to oxidative stress. The phospholipase $\mathrm{A}_{2}$-dependent activity of $\mathrm{Ca}^{2+}$ mediated by glutamatergic receptors liberates arachidonic acid (AA), which generates $\mathrm{O}_{2}{ }^{--}$through its metabolism by lipoxygenases and cyclooxygenases for eicosanoid formation [48].

The constant formation of $\mathrm{NO}^{\bullet}$ by the glia is neurotoxic because it increases the neuronal sensitivity to this reactive species. The neurotoxic action of $\mathrm{NO}^{*}$ is likely caused by the formation of peroxynitrite $\left(\mathrm{ONOO}^{-}\right)$, which is rapidly formed by the reaction of $\mathrm{NO}^{\bullet}$ with $\mathrm{O}_{2}{ }^{--}$. Under conditions of energy deficit and elevated intracellular $\mathrm{Ca}^{2+}$ concentration, xanthine oxidase generates $\mathrm{O}_{2}{ }^{-}$. . In this environment, lactic acid is generated, which promotes the release of $\mathrm{Fe}^{2+}$, the Haber-Weiss reaction, and the production of $\mathrm{HO}^{\bullet}$ [49]. Furthermore, $\mathrm{ONOO}^{-}$can react with tyrosine in proteins to form 3-nitrotyrosine (3-NT) [50]. 
TABLE 2: Effect of AEDs on the activity of antioxidant enzymes or oxidative stress markers in epileptic patients.

\begin{tabular}{|c|c|c|c|}
\hline AEDs & $\begin{array}{c}\text { Antioxidant enzymatic } \\
\text { activity/oxidative stress } \\
\text { markers }\end{array}$ & Findings & Ref \\
\hline VPA & GPx & $\begin{array}{l}\text { Kurekci et al., in 1995, found a significant increase in GPx activity in } \\
\text { children diagnosed with epilepsy. }\end{array}$ & {$[51]$} \\
\hline $\begin{array}{l}\text { VPA and } \\
\text { carbamazepine }\end{array}$ & $\begin{array}{l}\text { GSH, GPx, SOD, and } \\
\text { malonaldehyde (MDA) }\end{array}$ & $\begin{array}{l}\text { Cengiz et al., in 2000, evaluated the effect of VPA and carbamazepine on } \\
\text { the levels of GSH, GPx, SOD, and lipid peroxidation in the erythrocytes of } \\
30 \text { children diagnosed with epilepsy and compared with } 25 \text { healthy } \\
\text { children. The authors found that during a one-year treatment with VPA (in } \\
16 \text { children) or carbamazepine (in } 14 \text { children), the GPx levels were } \\
\text { significantly increased, but the GSH levels were significantly decreased. } \\
\text { With combined drugs, they were no significant differences in the SOD } \\
\text { activity and lipid peroxidation levels. }\end{array}$ & {$[52]$} \\
\hline $\begin{array}{l}\text { VPA and } \\
\text { carbamazepine }\end{array}$ & GPx, SOD, and MDA & $\begin{array}{l}\text { Yüksel et al., in } 2001 \text { and 2000, found a significant increase in the levels of } \\
\text { lipid peroxidation and decreased GPx activity in the serum of } 14 \text { children } \\
\text { treated with VPA for two years compared with that found in } 27 \text { healthy } \\
\text { children. The SOD serum levels increased significantly during the first year. } \\
\text { In } 13 \text { children diagnosed with epilepsy and then treated with } \\
\text { carbamazepine for two years, lipid peroxidation increased significantly in } \\
\text { the serum, compared with the control group. During the second year of } \\
\text { treatment with carbamazepine, the serum SOD levels were significantly } \\
\text { higher, compared with the control group and with the same group before } \\
\text { treatment. }\end{array}$ & {$[53,54]$} \\
\hline $\begin{array}{l}\text { VPA and } \\
\text { carbamazepine }\end{array}$ & $\mathrm{Se}, \mathrm{GPx}$, and $\mathrm{Cu} / \mathrm{Zn}-\mathrm{SOD}$ & $\begin{array}{l}\text { Verrotti et al., in 2002, found that } 36 \text { children with epilepsy and no } \\
\text { treatment exhibited no significant differences in the serum levels of Se, } \\
\text { GPx, and } \mathrm{Cu} / \mathrm{Zn} \text {-SOD, compared with the control group ( } 14 \text { children). One } \\
\text { year after beginning therapy with VPA (in } 22 \text { patients) or carbamazepine } \\
\text { (in } 14 \text { patients), the values of these parameters were unchanged. }\end{array}$ & {$[55]$} \\
\hline $\begin{array}{l}\text { VPA and } \\
\text { carbamazepine }\end{array}$ & SOD, GPx, and MDA & $\begin{array}{l}\text { Solowiej and Sobaniec, in 2003, found that } 25 \text { children treated with VPA, } 16 \\
\text { children treated with carbamazepine, and } 27 \text { children treated with } \\
\text { polytherapy (carbamazepine + VPA) exhibited a significant decrease in the } \\
\text { serum SOD activity, compared with } 61 \text { healthy children. The serum GPx } \\
\text { activity was significantly increased in all patient groups except in those } \\
\text { receiving combination therapy, compared with the control group. The lipid } \\
\text { peroxidation levels in the serum were significantly increased in all patients. }\end{array}$ & {$[56]$} \\
\hline VPA & GPx & $\begin{array}{l}\text { Hamed et al., in 2004, found that } 14 \text { adult patients without treatment } \\
\text { exhibited no significant decrease in GPx activity but exhibited a significant } \\
\text { reduction in the total antioxidant capacity in the serum. Fifty-five patients } \\
\text { with epilepsy treated using VPA exhibited a significant increase in their } \\
\text { serum GPx levels and total antioxidant capacity. }\end{array}$ & {$[57]$} \\
\hline OXC & GPx, SOD, and MDA & $\begin{array}{l}\text { Bolayir et al., in 2004, found that the GPx activity, SOD activity, and lipid } \\
\text { peroxidation levels in erythrocytes were significantly different after one } \\
\text { year of therapy with oxcarbazepine. This study was performed in } 13 \text { adult } \\
\text { patients, and the results were compared with the results obtained from } 15 \\
\text { healthy adults and from the same patients before monotherapy. }\end{array}$ & {$[58]$} \\
\hline VPA & MDA & $\begin{array}{l}\text { Martínez-Ballesteros et al., in 2004, found a significant increase in lipid } \\
\text { peroxidation in } 76 \text { patients compared with the control group. }\end{array}$ & [59] \\
\hline $\begin{array}{l}\text { VPA and } \\
\text { Carbamazepine }\end{array}$ & SOD, GPx, GR, and MDA & $\begin{array}{l}\text { Sobaniec et al., in 2006, evaluated the effect of therapy with AEDs and how } \\
\text { these drugs changed the SOD, GPx, and GR activity and the lipid } \\
\text { peroxidation levels in the erythrocytes of } 90 \text { pediatric patients and } 61 \\
\text { healthy children. The activity of the antioxidant enzymes was significantly } \\
\text { higher. The lipid peroxidation levels were significantly lower in children } \\
\text { treated only with carbamazepine. In children treated with VPA, the activity } \\
\text { of all antioxidant enzymes was lower. Higher levels of lipid peroxidation } \\
\text { were concurrently demonstrated. In patients treated with combination } \\
\text { therapy, the SOD activity was lower, whereas the activity of GPx and GR } \\
\text { was higher. In addition, lower lipid peroxidation levels were displayed. }\end{array}$ & {$[60]$} \\
\hline
\end{tabular}


TABLe 2: Continued.

\begin{tabular}{|c|c|c|c|}
\hline AEDs & $\begin{array}{l}\text { Antioxidant enzymatic } \\
\text { activity/oxidative stress } \\
\text { markers }\end{array}$ & Findings & Ref \\
\hline VPA & $\begin{array}{c}\mathrm{NO}^{\circ}, \mathrm{SOD}, \mathrm{CAT} \text {, and } \\
\mathrm{MDA}\end{array}$ & $\begin{array}{l}\text { Peker et al., in 2009, investigated the effect of VPA on the serum levels of } \\
\text { NO', lipid peroxidation, and certain antioxidant enzymes (SOD and CAT) } \\
\text { in } 21 \text { children treated with VPA for one year and in } 26 \text { healthy children. We } \\
\text { observed a significant increase of } 10 \% \text { in the levels of NO }{ }^{\circ} \text { in children } \\
\text { treated with VPA, compared with healthy children. There were no } \\
\text { significant differences in the levels of lipid peroxidation and antioxidant } \\
\text { enzymes. }\end{array}$ & {$[61]$} \\
\hline- & GPX and MDA & $\begin{array}{l}\text { Güneş et al., in } 2009 \text {, analyzed the erythrocyte antioxidant status of } 31 \\
\text { children with febrile seizures and } 30 \text { febrile children without seizures. The } \\
\text { levels of lipid peroxidation were significantly higher, and the GPx and SOD } \\
\text { levels were significantly lower in the group of children with febrile seizures } \\
\text { compared with the group that did not present with seizures. }\end{array}$ & {$[62]$} \\
\hline $\begin{array}{l}\text { VPA, } \\
\text { carbamazepine, } \\
\text { and levetiracetam }\end{array}$ & 8-OHG & $\begin{array}{l}\text { Varoglu et al., in 2010, determined in } 32 \text { patients treated with VPA, } 17 \\
\text { treated with carbamazepine, } 8 \text { with levetiracetam, and } 11 \text { with polytherapy } \\
\text { that the levels of low-density lipoprotein (LDL) and } 8 \text {-OHG were } \\
\text { significantly higher in all patients, compared with the control group. } \\
\text { Comparing the monotherapy versus the polytherapy, only the valproate + } \\
\text { levetiracetam combination yielded a significant increase in 8-OHG. }\end{array}$ & {$[63]$} \\
\hline OXC & $\mathrm{NO}^{\circ}$ and $\mathrm{MDA}$ & $\begin{array}{l}\text { Arhan et al., in 2011, found a significant decrease in the serum levels of } \mathrm{NO}^{\circ} \\
\text { and lipid peroxidation in } 16 \text { children diagnosed with idiopathic epilepsy } \\
\text { and treated for three months with OXC. }\end{array}$ & {$[64]$} \\
\hline VPA & $\begin{array}{l}\text { SOD, CAT, MPO, and } \\
\text { MDA }\end{array}$ & $\begin{array}{l}\text { Y.J. Zhang et al., in 2011, reported a significant decrease in the antioxidant } \\
\text { activity of SOD and CAT. They also found a significant increase in the } \\
\text { MPO activity and lipid peroxidation levels. This study was performed in } 26 \\
\text { epileptic children treated for six and } 12 \text { months with VPA, compared with } \\
30 \text { healthy children. }\end{array}$ & {$[65]$} \\
\hline
\end{tabular}

\section{Antioxidant Enzymes Induced by VPA, OXC, and TPM: Evidence in Humans and Experimental Models}

It is established that VPA, OXC, and TPM are capable of modulating the oxidant-antioxidant system. Particularly, enzyme antioxidant activity studies have demonstrated that the administration of certain AEDs causes decrease in enzyme activity, increase in the antioxidant system, or even the absence of an effect upon the antioxidant system.

VPA can modulate negatively or positively the enzymatic activity. Chaudhary and Parvez, in 2012, found a significant reduction of GST, GR, GPx, SOD, and CAT activity. They also observed significantly increased xanthine oxidase activity and lipid peroxidation levels in the cerebellum and cerebral cortex of rats [66]. Zhang et al., in 2011, observed a significant decrease in the antioxidant activity of SOD and CAT, a significant increase in the myeloperoxidase (MPO) activity, and increased levels of lipid peroxidation in epileptic children [65]. Varoglu et al., in 2010, observed significantly increased 8-hydroxyguanosine (8-OHG) levels in the serum of epileptic patients [63]; Peker et al., in 2009, found a significant increase of $\mathrm{NO}^{\circ}$ in the serum of epileptic children [61]. MartínezBallesteros et al., in 2004, observed significantly increased lipid peroxidation in epileptic patients treated with VPA [59]. Other studies have revealed a positive regulatory effect on the antioxidant activity of certain proteins [56, 67-69].
A few in vivo and in vitro studies have reported the effect of the OXC and TPM AEDs on the antioxidant defense system, the lipid peroxidation levels, and the ROS levels. Positive regulation of the antioxidant system by OXC has not been reported to date. Cardile et al. in 2001 and Pavone and Carile, in 2003, demonstrated increased ROS levels in cultured astrocytes, which caused negative regulation [70, 71]. Agarwal et al., in 2011, found significantly increased lipid peroxidation levels and significantly decreased levels of reduced glutathione (GSH) in rats with pentylenetetrazoleinduced epilepsy [72].

Cardile et al., in 2001, and Agarwal et al., in 2011, reported a negative regulatory effect of TPM. With respect to the positive regulatory effect of TPM on the antioxidant system, a significant increase in SOD, CAT, GPx, and neuronal nitric oxide synthase (nNOS) activities, as well as in GSH levels, has been observed. Significantly decreased lipid peroxidation levels have also been observed in experimental epilepsy models [43, 73-76]. Our research group has demonstrated for the first time that TPM has direct antioxidant activity in vitro against $\mathrm{O}_{2}{ }^{--}, \mathrm{H}_{2} \mathrm{O}_{2}, \mathrm{HO}^{*}$, and hypochlorous acid ( $\mathrm{HOCl})$ in a concentration-dependent manner. In this study, we demonstrated that the scavenging activity of TPM might explain its neuroprotective properties [77]. Human studies have evaluated the effects of AEDs on the antioxidant system; see Table 2. 
Although there is evidence in humans and experimental models that these AEDs (VPA, OXC, and TPM) modulate the activity of antioxidant enzymes, this evidence is not conclusive. It is necessary to study further how AEDs induce effects in antioxidant capacities in different types of epilepsy. In particular, our research group is interested in determining the activity of the antioxidant enzymes and their modulation by AEDs in epileptic pediatric patients.

\section{Therapeutic Relevance}

To date, the mechanisms involved in the etiopathogenesis of epilepsy remain unclear; however, the evidence showed that oxidative stress is involved in the epilepsy development. Therefore, the knowledge that current AEDs can modulate other systems opens a new therapeutic window for the population suffering from epilepsy and other chronic and degenerative CNS diseases, in which oxidative stress is one of the mechanisms underlying these pathologies.

\section{Conflict of Interests}

The authors of this work have no conflict of interests to declare.

\section{Acknowledgments}

We appreciate the financial support received from Protocols 04/2013 and 034/2013 of the Pediatrics National Institute and the technical assistance of Mr. Sergio Humberto LariosGodinez.

\section{References}

[1] T. Lara, "Análisis Clínico-epidemiológico de la Epilepsia en la hospitalización psiquiátrica del Instituto Nacional de Neurología y Neurocirugía "Manuel Velasco Suárez" Una revisión de cuatro años," Revista Argentina De Neurología, Psiquiatría Y Neurocirugía, vol. 35, no. 4, pp. 177-182, 2002.

[2] J. Engel Jr., "Concepts of epilepsy," Epilepsia, vol. 36, no. 1, pp. S23-S29, 1995.

[3] T. H. Lara and R. L. Ramírez, "Epidemiología de la Epilepsia en México. Un análisis interinstitucional de veinticinco años," Revista Neurologia, Neurocirugia Psiquiatria, vol. 33, pp. 11-20, 1993.

[4] M. P. Jacobs, G. D. Fischbach, M. R. Davis et al., "Future directions for epilepsy research," Neurology, vol. 57, no. 9, pp. 15361542, 2001.

[5] S. Auvin, E. Pineda, D. Shin, P. Gressens, and A. Mazarati, "Novel animal models of pediatric epilepsy," Neurotherapeutics, vol. 9, no. 2, pp. 245-261, 2012.

[6] ILAE, Commision on Classification and Terminology of the International League Against Epilepsy, "Proposal for revised clinical and electroencephalographic classification of epileptic seizures. From the Commission on Classification and Terminology of the International League Against Epilepsy," Epilepsia, vol. 22, no. 4, pp. 489-501, 1981.
[7] ILAE, "Proposal for revised classification of epilepsies and epileptic syndromes. Commission on Classification and Terminology of the International League Against Epilepsy," Epilepsia, vol. 30, no. 4, pp. 389-399, 1989.

[8] E. H. Reynolds, "Introduction: epilepsy in the world," Epilepsia, vol. 43 , no. 6, pp. 1-3, 2002.

[9] H. Sentíes-Madrid, "Guías del Capítulo Mexicano de la Liga Internacional contra la Epilepsia. Antiepilépticos de primera generación contra antiepilépticos de segunda generación: énfasis en efectos adversos de la segunda generación," 2012.

[10] S. D. Shorvon, "Drug treatment of epilepsy in the century of the ILAE: the second 50 years, 1959-2009," Epilepsia, vol. 50, no. 3, pp. 93-130, 2009.

[11] W. Löscher and D. Schmidt, "Modern antiepileptic drug development has failed to deliver: ways out of the current dilemma," Epilepsia, vol. 52, no. 4, pp. 657-678, 2011.

[12] W. Loscher, "In vivo administration of valproate reduces the nerve terminal (synaptosomal) activity of GABA aminotransferase in discrete brain areas of rats," Neuroscience Letters, vol. 160, no. 2, pp. 177-180, 1993.

[13] C. S. Biggs, B. R. Pearce, L. J. Fowler, and P. S. Whitton, “The effect of sodium valproate on extracellular GABA and other amino acids in the rat ventral hippocampus: an in vivo microdialysis study," Brain Research, vol. 594, no. 1, pp. 138-142, 1992.

[14] H. L. Rowley, C. A. Marsden, and K. F. Martin, "Differential effects of phenytoin and sodium valproate on seizure-induced changes in $\gamma$-aminobutyric acid and glutamate release in vivo," European Journal of Pharmacology, vol. 294, no. 2-3, pp. 541546, 1995.

[15] J. P. Vriend and N. A. M. Alexiuk, "Effects of valproate on amino acid and monoamine concentrations in striatum of audiogenic seizure-prone Balb/c mice," Molecular and Chemical Neuropathology, vol. 27, no. 3, pp. 307-324, 1996.

[16] J. P. Bolanos and J. M. Medina, "Evidence of stimulation of the $\gamma$ aminobutyric acid shunt by valproate and E- $\Delta 2$-valproate in neonatal rat brain," Molecular Pharmacology, vol. 43, no. 3, pp. 487-490, 1993.

[17] W. Loescher, "Effect of inhibitors of GABA Aminotransferase on the metabolism of GABA in brain tissue and synaptosomal fractions," Journal of Neurochemistry, vol. 36, no. 4, pp. 1521$1527,1981$.

[18] J. W. van der Laan, D. B. T. de Boer Th., and J. Bruinvels, "Di-npropylacetate and GABA degradation. Preferential inhibition of succinic semialdehyde dehydrogenase and indirect inhibition of GABA-transaminase," Journal of Neurochemistry, vol. 32, no. 6, pp. 1769-1780, 1979.

[19] S. R. Whittle and A. J. Turner, "Effects of anticonvulsant sodium valproate on $\gamma$-aminobutyrate and aldehyde metabolism in ox brain," Journal of Neurochemistry, vol. 31, no. 6, pp. 1453-1459, 1978.

[20] R. M. Collins Jr., H. R. Zielke, and R. C. Woody, "Valproate increases glutaminase and decreases glutamine synthetase activities in primary cultures of rat brain astrocytes," Journal of Neurochemistry, vol. 62, no. 3, pp. 1137-1143, 1994.

[21] F. M. Cutrer, V. Limmroth, G. Ayata, and M. A. Moskowitz, "Attenuation by valproate of c-fos immunoreactivity in trigeminal nucleus caudalis induced by intracisternal capsaicin," British Journal of Pharmacology, vol. 116, no. 8, pp. 3199-3204, 1995.

[22] M. L. Zeise, S. Kasparow, and W. Zieglgansberger, "Valproate suppresses N-methyl-D-aspartate-evoked transient depolarizations in the rat neocortex in vitro," Brain Research, vol. 544, no. 2, pp. 345-348, 1991. 
[23] P.-W. Gean, C.-C. Huang, C.-R. Hung, and J.-J. Tsai, "Valproic acid suppresses the synaptic response mediated by the NMDA receptors in rat amygdalar slices," Brain Research Bulletin, vol. 33, no. 3, pp. 333-336, 1994.

[24] J. P. Dreier and U. Heinemann, "Late low magnesium-induced epileptiform activity in rat entorhinal cortex slices becomes insensitive to the anticonvulsant valproic acid," Neuroscience Letters, vol. 119, no. 1, pp. 68-70, 1990.

[25] J. R. Buchhalter and M. A. Dichter, "Effects of valproic acid in cultured mammalian neurons," Neurology, vol. 36, no. 2, pp. 259-262, 1986.

[26] M. Farrant and R. A. Webster, "Neuronal activity, amino acid concentration and amino acid release in the substantia nigra of the rat after sodium valproate," Brain Research, vol. 504, no. 1, pp. 49-56, 1989.

[27] W. D. Gaillard, T. Zeffiro, S. Fazilat, C. DeCarli, and W. H. Theodore, "Effect of valproate on cerebral metabolism and blood flow: an 18F-2-deoxyglusose and $15 \mathrm{O}$ water positron emission tomography study," Epilepsia, vol. 37, no. 6, pp. 515-521, 1996.

[28] T. W. May, E. Korn-Merker, and B. Rambeck, "Clinical pharmacokinetics of oxcarbazepine," Clinical Pharmacokinetics, vol. 42, no. 12, pp. 1023-1042, 2003.

[29] A. Stefani, A. Pisani, M. de Murtas, N. B. Mercuri, M. G. Marciani, and P. Calabresi, "Action of GP 47779, the active metabolite of oxcarbazepine, on the corticostriatal system. II. Modulation of high-voltage-activated calcium currents," Epilepsia, vol. 36, no. 10, pp. 997-1002, 1995.

[30] P. C. Waldmeier, P. A. Baumann, P. Wicki, J.-J. Feldtrauer, C. Stierlin, and M. Schmutz, "Similar potency of carbamazepine, oxcarbazepine, and lamotrigine in inhibiting the release of glutamate and other neurotransmitters," Neurology, vol. 45, no. 10, pp. 1907-1913, 1995.

[31] R. J. DeLorenzo, S. Sombati, and D. A. Coulter, "Effects of topiramate on sustained repetitive firing and spontaneous recurrent seizure discharges in cultured hippocampal neurons," Epilepsia, vol. 41, no. 1, pp. S40-S44, 2000.

[32] H. S. White, S. D. Brown, J. H. Woodhead, G. A. Skeen, and H. H. Wolf, "Topiramate enhances GABA-mediated chloride flux and GABA-evoked chloride currents in murine brain neurons and increases seizure threshold," Epilepsy Research, vol. 28, no. 3, pp. 167-179, 1997.

[33] H. S. White, S. D. Brown, J. H. Woodhead, G. A. Skeen, and H. H. Wolf, "Topiramate modulates GABA-evoked currents in murine cortical neurons by a nonbenzodiazepine mechanism," Epilepsia, vol. 41, no. 1, pp. S17-S20, 2000.

[34] M. Valko, C. J. Rhodes, J. Moncol, M. Izakovic, and M. Mazur, "Free radicals, metals and antioxidants in oxidative stress-induced cancer," Chemico-Biological Interactions, vol. 160, no. 1, pp. $1-40,2006$.

[35] M. Inoue, E. F. Sato, M. Nishikawa et al., "Mitochondrial generation of reactive oxygen species and its role in aerobic life," Current Medicinal Chemistry, vol. 10, no. 23, pp. 2495-2505, 2003.

[36] S. Waldbaum and M. Patel, "Mitochondria, oxidative stress, and temporal lobe epilepsy," Epilepsy Research, vol. 88, no. 1, pp. 2345, 2010.

[37] N. Cardenas-Rodriguez, B. Huerta-Gertrudis, L. Rivera-Espinosa et al., "Role of oxidative stress in refractory epilepsy: evidence in patients and experimental models," International Journal of Molecular Sciences, vol. 14, no. 1, pp. 1455-1476, 2013.
[38] M. A. Ansari, A. S. Ahmad, M. Ahmad et al., "Selenium protects cerebral ischemia in rat brain mitochondria," Biological Trace Element Research, vol. 101, no. 1, pp. 73-86, 2004.

[39] S. C. Bondy, "The relation of oxidative stress and hyperexcitation to neurological disease," Proceedings of the Society for Experimental Biology and Medicine, vol. 208, no. 4, pp. 337-345, 1995.

[40] T. Dalton, "Temporalspatial patterns of expression of metallothionein-I and -III and other stress related genes in rat brain after kainic acid-induced seizures," Neurochemistry International, vol. 27, no. 1, pp. 59-71, 1995.

[41] M. Patel, B. J. Day, J. D. Crapo, I. Fridovich, and J. O. McNamara, "Requirement for superoxide in excitotoxic cell death," Neuron, vol. 16, no. 2, pp. 345-355, 1996.

[42] P. Uma Devi, K. Kolappa Pillai, and D. Vohora, "Modulation of pentylenetetrazole-induced seizures and oxidative stress parameters by sodium valproate in the absence and presence of N-acetylcysteine," Fundamental and Clinical Pharmacology, vol. 20, no. 3, pp. 247-253, 2006.

[43] A. Armaǧan, S. Kutluhan, M. Yilmaz et al., "Topiramate and vitamin E modulate antioxidant enzyme activities, nitric oxide and lipid peroxidation levels in pentylenetetrazol-induced nephrotoxicity in rats," Basic and Clinical Pharmacology and Toxicology, vol. 103, no. 2, pp. 166-170, 2008.

[44] M. V. Frantseva, J. L. Perez Velazquez, G. Tsoraklidis et al., "Oxidative stress is involved in seizure-induced neurodegeneration in the kindling model of epilepsy," Neuroscience, vol. 97, no. 3, pp. 431-435, 2000.

[45] U. Schweizer, A. U. Bräuer, J. Köhrle, R. Nitsch, and N. E. Savaskan, "Selenium and brain function: a poorly recognized liaison," Brain Research Reviews, vol. 45, no. 3, pp. 164-178, 2004.

[46] R. Kovács, S. Schuchmann, S. Gabriel, O. Kann, J. Kardos, and U. Heinemann, "Free radical-mediated cell damage after experimental status epilepticus in hippocampal slice cultures," Journal of Neurophysiology, vol. 88, no. 6, pp. 2909-2918, 2002.

[47] H. S. White, M. D. Smith, and K. S. Wilcox, "Mechanisms of action of antiepileptic drugs," International Review of Neurobiology, vol. 81, pp. 85-110, 2007.

[48] P. Singh, K. A. Mann, H. K. Mangat, and G. Kaur, "Prolonged glutamate excitotoxicity: effects on mitochondrial antioxidants and antioxidant enzymes," Molecular and Cellular Biochemistry, vol. 243, no. 1-2, pp. 139-145, 2003.

[49] D. N. Granger, "Role of xanthine oxidase and granulocytes in ischemia-reperfusion injury," American Journal of PhysiologyHeart and Circulatory Physiology, vol. 255, no. 6, part 2, pp. H1269-H1275, 1988.

[50] K. Hensley, M. L. Maidt, Q. N. Pye et al., "Quantitation of protein-bound 3-nitrotyrosine and 3,4-dihydroxyphenylalanine by high-performance liquid chromatography with electrochemical array detection," Analytical Biochemistry, vol. 251, no. 2, pp. 187195, 1997.

[51] A. E. Kurekci, F. Alpay, S. Tanindi et al., "Plasma trace element, plasma glutathione peroxidase, and superoxide dismutase levels in epileptic children receiving antiepileptic drug therapy," Epilepsia, vol. 36, no. 6, pp. 600-604, 1995.

[52] M. Cengiz, A. Yüksel, and M. Seven, "The effects of carbamazepine and valproic acid on the erythrocyte glutathione, glutathione peroxidase, superoxide dismutase and serum lipid peroxidation in epileptic children," Pharmacological Research, vol. 41, no. 4, pp. 423-425, 2000.

[53] A. Yüksel, M. Cengiz, M. Seven, and T. Ulutin, "Erythrocyte glutathione, glutathione peroxidase, superoxide dismutase and 
serum lipid peroxidation in epileptic children with valproate and carbamazepine monotherapy," Journal of Basic and Clinical Physiology and Pharmacology, vol. 11, no. 1, pp. 73-81, 2000.

[54] A. Yüksel, M. Cengiz, M. Seven, and T. Ulutin, "Changes in the antioxidant system in epileptic children receiving antiepileptic drugs: two-year prospective studies," Journal of Child Neurology, vol. 16, no. 8, pp. 603-606, 2001.

[55] A. Verrotti, F. Basciani, D. Trotta, M. P. Pomilio, G. Morgese, and F. Chiarelli, "Serum copper, zinc, selenium, glutathione peroxidase and superoxide dismutase levels in epileptic children before and after 1 year of sodium valproate and carbamazepine therapy," Epilepsy Research, vol. 48, no. 1-2, pp. 71-75, 2002.

[56] E. Sołowiej and W. Sobaniec, "The effect of antiepileptic drug therapy on antioxidant enzyme activity and serum lipid peroxidation in young patients with epilepsy," Neurologia i Neurochirurgia Polska, vol. 37, no. 5, pp. 991-1003, 2003.

[57] S. A. Hamed, M. M. Abdellah, and N. El-Melegy, "Blood levels of trace elements, electrolytes, and oxidative stress/antioxidant systems in epileptic patients," Journal of Pharmacological Sciences, vol. 96, no. 4, pp. 465-473, 2004.

[58] E. Bolayir, K. Celik, A. Tas, S. Topaktas, and S. Bakir, "The effects of oxcarbazepine on oxidative stress in epileptic patients," Methods and Findings in Experimental and Clinical Pharmacology, vol. 26, no. 5, pp. 345-348, 2004.

[59] C. Martínez-Ballesteros, E. Pita-Calandre, Y. Sánchez-González, C. M. Rodríguez-López, and A. Agil, "Lipid peroxidation in adult epileptic patients treated with valproic acid," Revista de Neurologia, vol. 38, no. 2, pp. 101-106, 2004.

[60] W. Sobaniec, E. Solowiej, W. Kulak, L. Bockowski, J. SmigielskaKuzia, and B. Artemowicz, "Evaluation of the influence of antiepileptic therapy on antioxidant enzyme activity and lipid peroxidation in erythrocytes of children with epilepsy," Journal of Child Neurology, vol. 21, no. 7, pp. 558-562, 2006.

[61] E. Peker, S. Oktar, M. Ari et al., "Nitric oxide, lipid peroxidation, and antioxidant enzyme levels in epileptic children using valproic acid," Brain Research, vol. 1297, pp. 194-197, 2009.

[62] S. Güneş, E. Dirik, U. Yiş et al., "Oxidant status in children after febrile seizures," Pediatric Neurology, vol. 40, no. 1, pp. 47-49, 2009.

[63] A. O. Varoglu, A. Yildirim, R. Aygul, O. L. Gundogdu, and Y. N. Sahin, "Effects of valproate, carbamazepine, and levetiracetam on the antioxidant and oxidant systems in epileptic patients and their clinical importance," Clinical Neuropharmacology, vol. 33, no. 3, pp. 155-157, 2010.

[64] E. Arhan, A. Serdaroglu, B. Ozturk et al., "Effects of epilepsy and antiepileptic drugs on nitric oxide, lipid peroxidation and xanthine oxidase system in children with idiopathic epilepsy," Seizure, vol. 20, no. 2, pp. 138-142, 2011.

[65] Y. J. Zhang, M. Zhang, X. C. Wang et al., "Effects of sodium valproate on neutrophils' oxidative metabolism and oxidant status in children with idiopathic epilepsy," Chinese Journal of Pediatrics, vol. 49, no. 10, pp. 776-781, 2011.

[66] S. Chaudhary and S. Parvez, "An in vitro approach to assess the neurotoxicity of valproic acid-induced oxidative stress in cerebellum and cerebral cortex of young rats," Neuroscience, vol. 225, pp. 258-268, 2012.

[67] U. Yiş, E. Seçkin, S. H. Kurul, F. Kuralay, and E. Dirik, "Effects of epilepsy and valproic acid on oxidant status in children with idiopathic epilepsy," Epilepsy Research, vol. 84, no. 2-3, pp. 232237, 2009.

[68] A. Aycicek and A. Iscan, "The effects of carbamazepine, valproic acid and phenobarbital on the oxidative and antioxidative bala- nce in epileptic children," European Neurology, vol. 57, no. 2, pp. 65-69, 2007.

[69] Ş. Seçkin, C. Başaran-Küçükgergin, and M. Uysal, "Effect of acute and chronic administration of sodium valproate on lipid peroxidation and antioxidant system in rat liver," Pharmacology and Toxicology, vol. 85, no. 6, pp. 294-298, 1999.

[70] V. Cardile, A. Pavone, M. Renis, T. Maci, and V. Perciavalle, "Effects of gabapentin and topiramate in primary rat astrocyte cultures," NeuroReport, vol. 12, no. 8, pp. 1705-1708, 2001.

[71] A. Pavone and V. Cardile, "An in vitro study of new antiepileptic drugs and astrocytes," Epilepsia, vol. 44, no. 10, pp. 34-39, 2003.

[72] N. B. Agarwal, N. K. Agarwal, P. K. Mediratta, and K. K. Sharma, "Effect of lamotrigine, oxcarbazepine and topiramate on cognitive functions and oxidative stress in PTZ-kindled mice," Seizure, vol. 20, no. 3, pp. 257-262, 2011.

[73] M. Muriach, R. López-Pedrajas, J. M. Barcia, M. V. SanchezVillarejo, I. Almansa, and F. J. Romero, "Cocaine causes memory and learning impairments in rats: involvement of nuclear factor kappa B and oxidative stress, and prevention by topiramate," Journal of Neurochemistry, vol. 114, no. 3, pp. 675-684, 2010.

[74] S. Kutluhan, M. Naziroğlu, Ö. Çelik, and M. Yilmaz, "Effects of selenium and topiramate on lipid peroxidation and antioxidant vitamin levels in blood of pentylentetrazol-induced epileptic rats," Biological Trace Element Research, vol. 129, no. 1-3, pp. 181189, 2009.

[75] M. Naziroğlu, A. C. Uğuz, A. Gokçimen et al., "Tenoxicam modulates antioxidant redox system and lipid peroxidation in rat brain," Neurochemical Research, vol. 33, no. 9, pp. 1832-1837, 2008.

[76] M. Kubera, B. Budziszewska, L. Jaworska-Feil et al., "Effect of topiramate on the kainate-induced status epilepticus, lipid peroxidation and immunoreactivity of rats," Polish Journal of Pharmacology, vol. 56, no. 5, pp. 553-561, 2004.

[77] N. Cardenas-Rodriguez, E. Coballase-Urrutia, B. Huerta-Gertrudis et al., "Antioxidant activity of topiramate: an antiepileptic agent," Neurological Sciences, vol. 34, no. 5, pp. 741-747, 2013. 


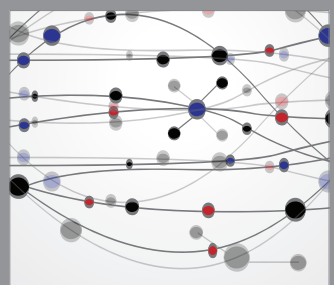

The Scientific World Journal
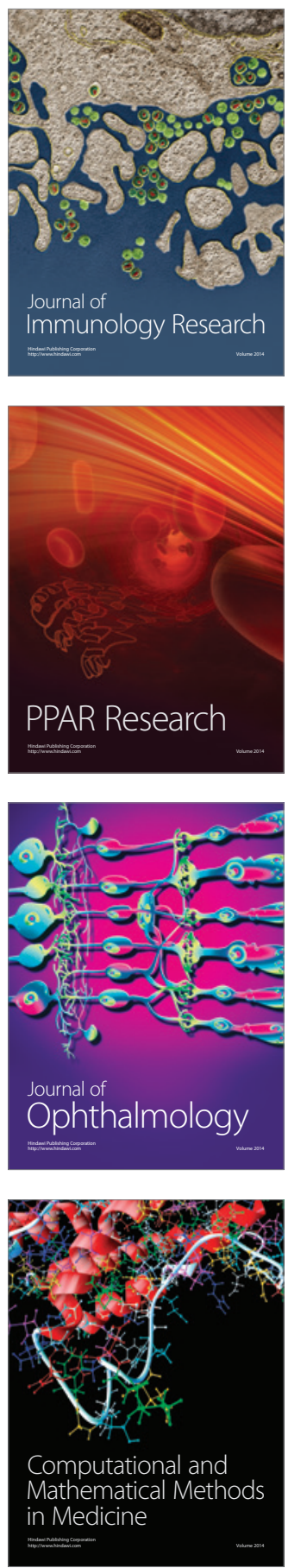

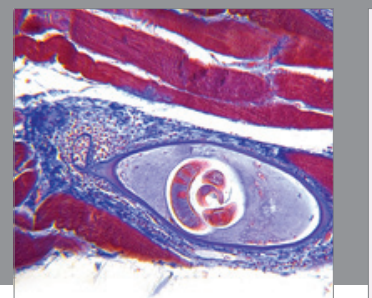

Gastroenterology

Research and Practice
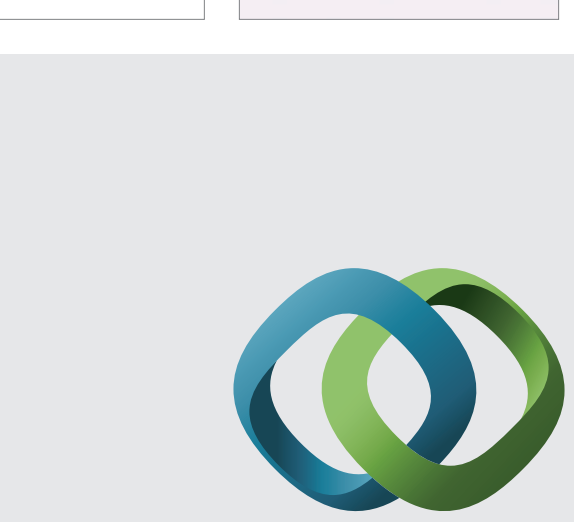

\section{Hindawi}

Submit your manuscripts at

http://www.hindawi.com
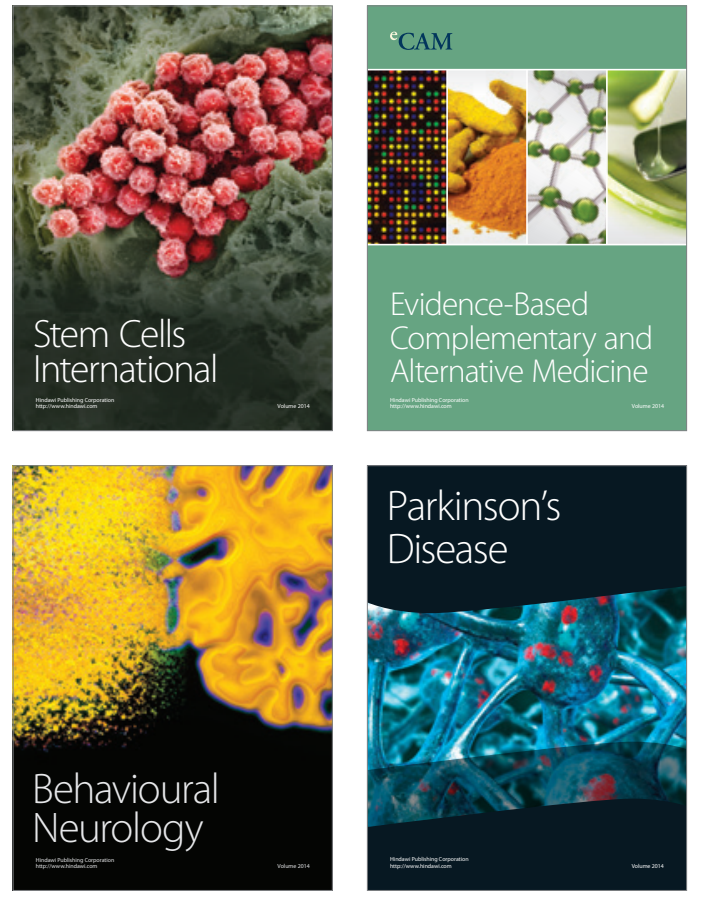
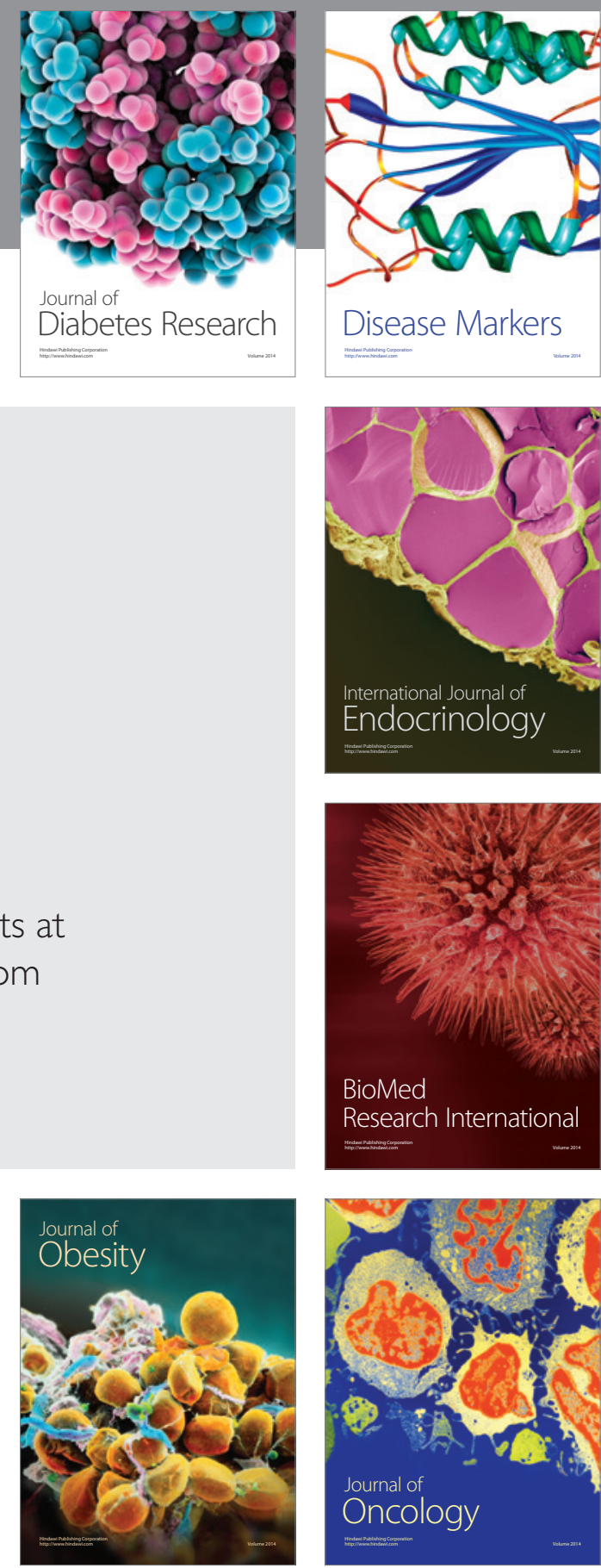

Disease Markers
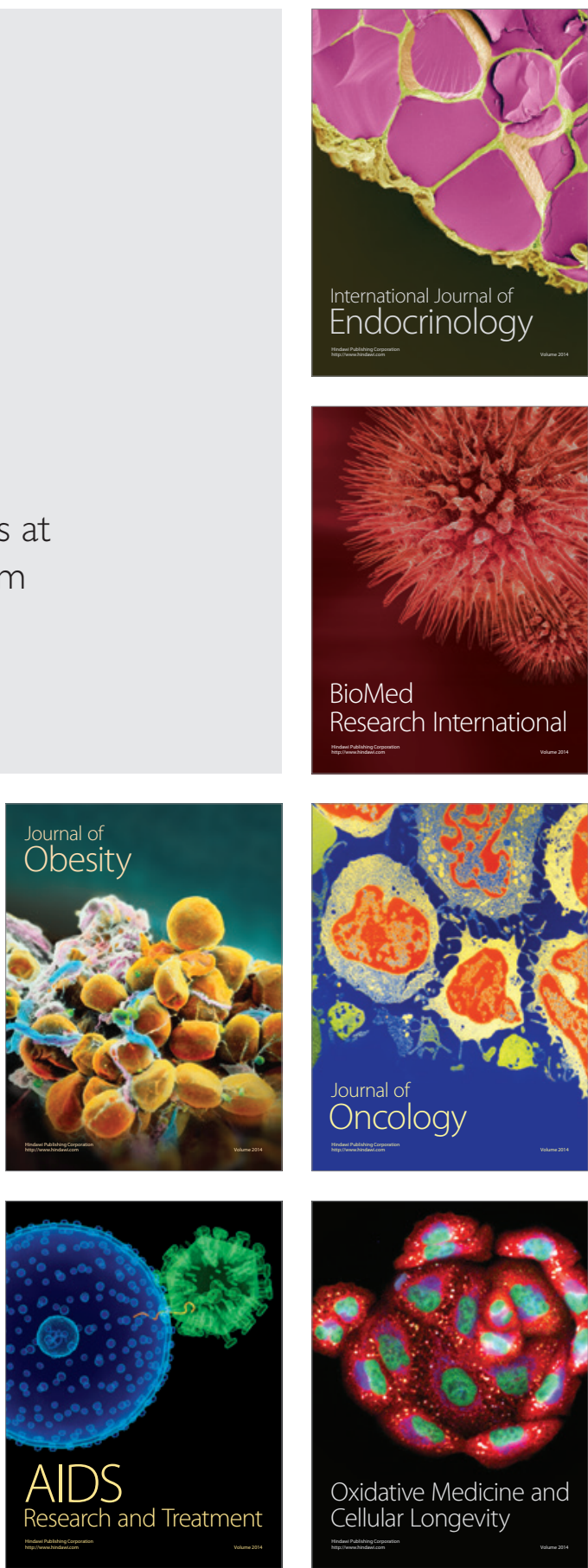